\title{
Caracterização estrutural de geopolímeros sustentáveis de escória de aciaria LD e escória de aciaria LF com KOH
}

\author{
Structural characterization of sustainable \\ geopolymers of steel slag LD and steel slag LF with \\ $\mathrm{KOH}$
}

Ana Paula dos Santos Pereira ${ }^{1}$, Flavio James Humberto Tommasini Viera Ramos ${ }^{1,2}$, Marcelo Henrique Prado da Silva ${ }^{1}$

\author{
${ }^{1}$ Laboratório de Cerâmicos, IME/SE8 - Departamento de Ciência dos Materiais, Praça General Tibúrcio, 80, Urca, Rio de \\ Janeiro, RJ, Brasil. \\ ${ }^{2}$ Laboratório de Catálise e Polimerização, Instituto de Macromoléculas Professora Eloisa Mano (IMA/UFRJ), Departa- \\ mento de Ciências e Tecnologia de Polímeros, Av. Horácio Macedo, 2030 - Cidade Universitária da Universidade Federal \\ do Rio de Janeiro, RJ, Brasil. \\ e-mail: anapaula_pereira99@hotmail.com, fallmasini@gmail.com,marceloprado@ime.eb.br
}

\begin{abstract}
RESUMO
A produção de compósitos à base de produtos derivados de resíduos industriais conduziu o presente estudo, agregando valor aos resíduos de indústrias metalúrgicas e siderúrgicas, o que é revertido em bem à sociedade. Os materiais geopoliméricos podem ser uma das soluções para a destinação dos resíduos industriais gerados por esses setores. O objetivo do estudo foi investigar a relação entre sólido/líquido para produção de corpos-de-prova obtidos pela reação de geopolimerização, utilizando escória de aciaria de convertedor e de panela, ou seja, processo de Linz Donawitz (LD) e de ladle furnace (LF), respectivamente. As amostras dos resíduos foram sintetizadas a partir de uma solução alcalina de hidróxido de potássio 8 $\mathrm{M}(\mathrm{KOH})$, nas proporções de 1.2; 1.4 e $1.6 \mathrm{~g} / \mathrm{v}$ (sólido/líquido). As análises de composição química, estabilidade térmica, microestrutura, quantificação de fases cristalinas e porosidade foram realizadas por espectroscopia de fluorescência de raios X (FRX), espectroscopia de infravermelho por transformada de Fourier (FTIR), análise termogravimétrica (TGA), microscopia eletrônica de varredura com fonte de emissão de campo (MEV-FEG), difratometria de raios X (DRX) e determinação de densidade pelo princípio de Arquimedes. Os resultados indicaram que os geopolímeros obtidos a partir das escórias de aciaria geraram peças com estabilidade dimensional e altas possibilidades de aplicações como materiais de engenharia. Observou-se que a razão solido/líquido foi um ponto importante na síntese dos compósitos, uma vez que as amostras com razão 1.6 apresentaram um aspecto com maior coesão entre as partículas e maiores valores de densificação em relação às amostras com razões 1.2 e 1.4 .
\end{abstract}

Palavras-chave: Geopolímero; Escória de aciaria; Sustentabilidade, Resíduos, Materiais de Engenharia.

\begin{abstract}
Production of composites based on derivative products of industrial wastes was presented in this study, which aggregate value to metallurgical, steelmaker wastes of the industries, and this is reversed in beneficial effects to society. Geopolymeric materials can be a solution to industrial residues generated for these sectors. The objective of study was the investigation between a solid/liquid relationship to production of specimens obtained from geopolymerization reaction, using steelmaking slags by process of Linz Donawitz (LD) and ladle furnace (LF), respectively. Samples of the residues were synthesized from an alkaline solution of $8 \mathrm{M}$ potassium hydroxide $(\mathrm{KOH})$ in the 1.2, 1.4 and $1.6 \mathrm{~g} / \mathrm{v}$ proportions (solid/liquid). Analyses of chemical composition, thermal stability, microstructure, amount of crystallinity phases and porosity were evaluated to XRF, FTIR, TGA, SEM-FEG and Archimedes' principle obtained by reaction geopolymerization through the steelmaking slags (LF and LD), respectively. The results indicated that obtained geopolymers from steelmaking slags developed specimens with dimensional stability and high possibilities of applications, as engineering materials. The results indicate that the solid / liquid ratio is an important point in the geopolymerization process, since the 1.6 samples presented a more cohesive
\end{abstract}


appearance and higher densification values than the 1.2 and 1.4 samples.

Keywords: Geopolymer; Steelmaking slag; Sustainability, Waste, Engineering Materials.

\section{INTRODUÇÃO}

Os geopolímeros são materiais semicristalinos originados da reação de um precursor de aluminossilicatos com uma solução concentrada de silicato de sódio ou hidróxido de metal alcalino [1-2]. O valor da tecnologia dos geopolímeros reside na sua capacidade em produzir ligantes com elevado desempenho a partir de materiais residuais, como cinza volante, escória de alto forno, escória de aciaria, metacaulim, cinzas de casca de arroz, lama vermelha, dentre outros. A conversão desses resíduos industriais em produtos úteis à sociedade tem sido muito explorada. Geopolímeros produzidos a partir de escórias têm sido reportados como um dos materiais sustentáveis de construção civil mais promissores do século XXI [3-4].

O conceito básico para síntese de geopolímeros envolve a composição de uma rede de aluminossilicatos composta por unidades tetraédricas $\left[\mathrm{AlO}_{4}\right]^{5-}$ e octaédricas $\left[\mathrm{SiO}_{4}\right]^{4-}$ que derivam da reação entre um ativador alcalino e os precursores aluminossilicatos. Esses materiais podem ser de origem natural, como as argilas naturais, ou de origem artificial, como os resíduos industriais e seus subprodutos [5-6]. A reação de síntese de geopolímeros ocorre por um processo químico de dissolução alcalina e posterior precipitação em uma solução aquosa; assim, após um período, o material passa por um enrijecimento e a resistência do geopolímero é alcançada. Assim o sistema de reação de geopolimerização tem sido objeto de estudos de muitos pesquisadores e o princípio geral é muito bem definido [1,18].

O mecanismo de geopolimerização é dividido em quatro etapas que consistem nas reações de dissolução, coagulação, condensação e cristalização. A primeira etapa consiste na ruptura das ligações covalentes Si-O-Si e Al-O-Si, e ocorre em pH altamente alcalino com a formação de grupamentos que originam uma fase coloidal. A segunda etapa decorre do acúmulo de produtos oriundos das quebras de ligações, que interagem entre si e formam uma estrutura coagulada. A terceira etapa consiste na geração de uma estrutura condensada. A quarta etapa envolve a cristalização do material condensado [2-8, $24,26,28]$.

Alguns estudos demonstraram que as propriedades dos geopolímeros são afetadas pela variação da razão Si/Al, o que influencia na reatividade dos componentes. Portanto, a compreensão da reatividade das matérias-primas em um ambiente alcalino é importante para decisão das composições iniciais para síntese e alcance das propriedades desejadas [19-21]. Um exemplo de resíduo industrial muito pesquisado tem sido as escórias de aciaria que são subprodutos originados da conversão de minério de ferro ou rejeitos de ferro produzidos pela indústria siderúrgica [15]. O grande volume gerado e a forma inadequada de armazenamento justificam a utilização das escórias de aciaria para o desenvolvimento sustentável. Portanto, grande quantidade dessa escória vem sendo utilizada como material de preenchimento, modificador de solo e para o processo de produção de cimento [9-12].

No contexto do desenvolvimento sustentável, o processo de geopolimerização é considerado como uma tecnologia limpa e economicamente viável, uma vez que resíduos industriais e produtos compostos por aluminossilicatos podem ser utilizados na fabricação de construção com alta resistência mecânica e baixo custo [12-14]. Esta pesquisa está relacionada à investigação da morfologia, formação estrutural e comportamento térmico dos geopolímeros. Entretanto, a composição e quantificação dos elementos presentes nos materiais precursores também foram consideradas. As possíveis inovações e funcionalidades nas propriedades geradas pelos produtos a partir das escórias de aciaria podem favorecer o processo de reutilização dos resíduos industriais, bem como o desenvolvimento de novos materiais com elevado desempenho, para determinadas aplicações como materiais de engenharia.

\section{MATERIAIS E MÉTODOS}

Os geopolímeros foram produzidos em diferentes proporções sólido/líquido, pela razão entre a massa de escória particulada e o volume de solução alcalina. Os materiais foram sintetizados nas seguintes proporções: 1.2; 1.4 e $1.6 \mathrm{~g} / \mathrm{v}$. As escórias de aciaria utilizadas foram fornecidas pela Usiminas Ltda, em formato de cascalho (granulado), sendo oriundas de diferentes etapas da produção do aço, uma do conversor LD (convertedor) e a outra do forno LF (panela).

Na etapa inicial, os materiais foram submetidos à redução do tamanho de partículas, através de um moinho de bolas, e passaram por uma peneira com abertura de $74 \mu \mathrm{m}$. O material precursor para alcalinização da solução foi hidróxido de potássio $(\mathrm{KOH})$ na concentração de 8 molar. Posteriormente, a solução foi adicionada às escórias, sob agitação mecânica constante, durante o período de 5 minutos. A mistura foi vertida em moldes circulares com $3 \mathrm{~cm}$ de diâmetro para o processo de cura. O período do processo de geopolimerização ocorreu em temperatura ambiente $\left(25^{\circ} \mathrm{C}\right)$, com tempo de secagem de 24 horas. Posteriormente, as peças foram desmoldadas para serem submetidas às análises. A Figura 1 são apresentados os corpos de prova desmoldados.

A análise química da escória foi realizada por espectroscopia de fluorescência de raios X (FRX) utilizando um equipamento X EDX-700, Shimadzu. Os grupos funcionais presentes nas amostras foram identificados por espectroscopia de infravermelho com transformada de Fourier (FTIR). O equipamento utilizado foi um modelo IRAffinity-1S FTIR, fabricado pela Shimadzu, com a faixa de comprimento de onda com varredura de 4000- $400 \mathrm{~cm}-1$. As fases cristalinas das escórias e geopolímeros foram identificadas por difração de raios X (DRX), com radiação $\mathrm{Cu}-\mathrm{K} \alpha$ em difratômetro Panalytical X'Pert Pro. 

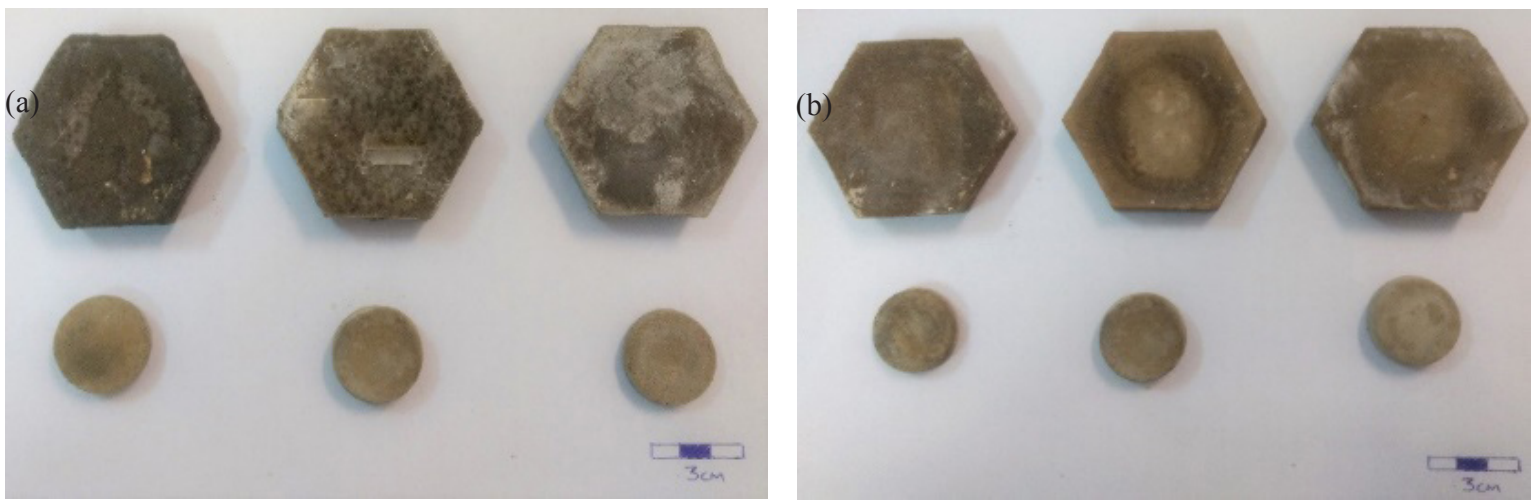

Figura 1: Copos de prova escória de aciaria de convertedor (a) e panela (b), proporções de 1.2, 1.4 e 1.6 (da esquerda para direita), respectivamente.

A determinação das fases cristalinas presentes nas amostras foi obtida através do refinamento pelo método Rietveld, o qual consiste na comparação do padrão de difração calculado com o padrão de difração obtido experimentalmente. $\mathrm{O}$ ajuste é realizado utilizando-se o método dos mínimos quadrados. A partir dessa técnica, foram extraídas informações quantitativas correspondentes às fases presentes e a estrutura cristalina presente nas amostras. Portanto pela análise, as fases obtidas foram comparadas com fichas cristalográficas presentes no banco de dados da Inorganic Cristal Structure Databese (ICSD). O percentual das fases foi estabelecido por meio do software TOPAS-Academic versão 4.1, que utiliza o método Rietveld através de uma comparação dos dados experimentais com os dados teóricos através de ajustes matemáticos.

A microestrutura do geopolímero foi observada em um microscópio eletrônico de varredura (MEV-FEG), modelo QUANTA FEG 250, fabricado pela FEI Company. A análise para observação do comportamento térmico das amostras foi apresentada através da análise térmica diferencial (DTA) e análise termogravimétrica (TGA), a qual foi realizada através do equipamento modelo DTG-60 H, fabricado pela Shimadzu. Os parâmetros utilizados para a análise foram obtidos à uma taxa de aquecimento de $10^{\circ} \mathrm{C} / \mathrm{min}$, sob atmosfera inerte de nitrogênio gasoso $\left(\mathrm{N}_{2}\right)$, na faixa de temperatura de $0^{\circ} \mathrm{C}$ à $1000^{\circ} \mathrm{C}$.

A determinação da densidade e possível porosidade criada nos corpos cerâmicos foi realizada pelo princípio de Arquimedes, de acordo com a norma ABNT NBR 16661 (2017). Os dados obtidos possibilitaram o cálculo do volume aparente de acordo com a equação (1), onde $\mathrm{Mu}=$ massa úmida; $\mathrm{Mi}=$ massa imersa e $\rho \mathrm{e}=$ massa específica do líquido

$$
\mathrm{V}_{\mathrm{a}}=\left(\mathrm{M}_{\mathrm{u}}-\mathrm{M}_{\mathrm{i}}\right) / \rho_{\mathrm{e}}
$$

A porosidade aparente $\left(\mathrm{P}_{\mathrm{a}}\right)$, densidade aparente $\left(\mathrm{D}_{\mathrm{a}}\right)$ e densificação (D) são dadas pelas equações (2), (3) (4), sendo $\mathrm{M}_{\mathrm{s}}=$ massa seca e $\mathrm{D}_{\mathrm{t}}=$ densidade teórica.

$$
\begin{gathered}
P_{a}(\%)=\left[\left(\left(M_{u}-M_{i}\right) /\left(\rho_{e} \times V_{a}\right)\right] \times 100\right. \\
D_{a}=M_{s} / V_{a} \\
D(\%)=\left(D_{a} / D_{t}\right) \times 100
\end{gathered}
$$

\section{RESULTADOS E DISCUSSÃO}

\subsection{Análise de Fluorescência de raios X (FRX)}

A análise de fluorescência de raios X (FRX) apresentou a composição química das escórias de aciaria de convertedor (ELD) e de panela (ELF) adquiridas como recebidas, assim como visualizada através da Tabela 1. A partir da análise foi possível indicar a razão de possíveis aluminossilicatos presentes nas amostras, assim como as razões elevadas de óxidos de cálcio $(\mathrm{CaO})$, silício $\left(\mathrm{SiO}_{2}\right)$, alumínio $\left(\mathrm{Al}_{2} \mathrm{O}_{3}\right)$ e ferro $\left(\mathrm{Fe}_{2} \mathrm{O}_{3}\right)$. Esses fatores podem indicar a possibilidade da utilização desses materiais para aplicações que exijam alguma propriedade de absorção de ondas sonoras, estabilidade térmica, inércia química e melhor característica na estabilidade dimensional [19, 22, 27]. Os resultados da análise de fluorescência de raio X das amostras estão apresentados na Tabela 1. 
Tabela 1: Resultados da análise de fluorescência de raios X (FRX) para as escórias de convertedor e panela, respectivamente.

\begin{tabular}{ccc}
\hline \multirow{2}{*}{$\begin{array}{c}\text { Quantificação } \\
\text { dos Elementos }\end{array}$} & \multicolumn{2}{c}{ Proporção (\%) } \\
\cline { 2 - 3 } & $\begin{array}{c}\text { Escória de } \\
\text { Convertedor (LD) }\end{array}$ & $\begin{array}{c}\text { Escória de } \\
\text { Panela (LF) }\end{array}$ \\
\hline $\mathbf{C a O}$ & 51,47 & 53,58 \\
\hline $\mathbf{S i O}_{2}$ & 10,63 & 9,40 \\
\hline $\mathrm{Al}_{2} \mathbf{O}_{3}$ & 1,49 & 6,92 \\
\hline $\mathbf{M g O}$ & 3,66 & 9,30 \\
\hline $\mathbf{S O}_{3}$ & 0,21 & 4,61 \\
\hline $\mathrm{Fe}_{2} \mathbf{O}_{3}$ & 25,65 & 15,99 \\
\hline $\mathbf{M n O}$ & 2,55 & 1,84 \\
\hline $\mathrm{TiO}_{2}$ & -- & 0,40 \\
\hline
\end{tabular}

\subsection{Princípio de Arquimedes}

A densidade aparente, porosidade aparente e densificação de todas as amostras foram calculadas pelo método de Arquimedes, seguindo a norma técnica ABNT NBR 16661:2017. Os valores dos parâmetros obtidos estão apresentados na Tabela 2. Esses resultados apresentam a média aritmética das medidas entre as três amostras para cada proporção. Portanto, através dessa técnica foram determinados os valores da densificação e porosidade dos geopolímeros sintetizados. Assim, os valores de densidade teórica utilizadas para os cálculos foram de $3,35 \mathrm{~g} / \mathrm{cm}^{3}$ para a escória de aciaria e $3,40 \mathrm{~g} / \mathrm{cm}^{3}$ para escória de panela [16-17].

Tabela 2: Densificação dos distintos geopolímeros produzidos durante com as escórias de convertedor e panela, a partir da dissolução do hidróxido de potássio $(\mathrm{KOH})$, respectivamente.

\begin{tabular}{cccc|ccc}
\hline \multirow{2}{*}{$\begin{array}{c}\text { Razão } \\
\text { sólido/ } \\
\text { líquido }\end{array}$} & \multicolumn{2}{c|}{ Escória de Convertedor (LD) } & \multicolumn{3}{c}{ Escória de Panela (LF) } \\
\cline { 2 - 7 } & $\begin{array}{c}\text { Porosidade } \\
\text { aparente (\%) }\end{array}$ & $\begin{array}{c}\text { Densidade } \\
\text { aparente (g/ } \\
\mathbf{c m}^{\mathbf{3}} \text { ) }\end{array}$ & $\begin{array}{c}\text { Densificação } \\
\mathbf{( \% )}\end{array}$ & $\begin{array}{c}\text { Porosidade } \\
\text { aparente (\%) }\end{array}$ & $\begin{array}{c}\text { Densidade } \\
\text { aparente (g/a } \\
\mathbf{c m}^{\mathbf{3}} \text { ) }\end{array}$ & $\begin{array}{c}\text { Densificação } \\
\text { (\%) }\end{array}$ \\
\hline $\mathbf{1 . 2}$ & 46,81 & 1,69 & 22,03 & 36,27 & 0,99 & 39,67 \\
\hline $\mathbf{1 . 4}$ & 43,16 & 1,76 & 24,68 & 34,82 & 1,11 & 43,57 \\
\hline $\mathbf{1 . 6}$ & 39,12 & 1,97 & 26,15 & 24,35 & 1,20 & 48,17 \\
\hline
\end{tabular}

Para as amostras de escória de convertedor e escória de panela, os resultados obtidos corroboram com as análises feita através das micrografias de MEV-FEG, no qual mostram que a proporção de 1.6 apresentou uma microestrutura mais coesa. Esse efeito pode colaborar com o maior valor de densificação apresentado por esse tipo de amostra, em relação as demais proporções de amostras geopoliméricas produzidas. Em relação ao tipo de escórias utilizadas, os geopolímeros produzidos com a escória de aciaria de panela apresentaram maiores densificações, como podem ser observadas nas imagens da microestrutura obtida através da microscopia eletrônica de varredura (Figura 6), em comparação aos geopolímeros produzidos com a escória de convertedor (Figura 7). Esses fatores corroboram com os resultados dos valores obtidos através do princípio de Arquimedes.

\subsection{Análise de Espectroscopia de Infravermelho por Transformada Fourier (FTIR)}

A identificação dos grupos funcionais identificados nas escórias de aciaria de panela e convertedor antes da síntese de geopolimerização foram relacionadas a composição do processo de produção e origem do minério de ferro para fabricação do aço carbono. Os resultados corroboram com as quantificações distintas apresentadas pelas respectivas escórias analisadas. Os principais grupos funcionais observados correspondem aos elementos encontrados em termos de óxidos presentes nas escórias de aciaria na pesquisa foram $\mathrm{CaO}, \mathrm{Fe}_{2} \mathrm{O}_{3}, \mathrm{SiO}_{2}, \mathrm{MgO}, \mathrm{Al}_{2} \mathrm{O}_{3}$ e $\mathrm{MnO}$, como observados pela análise de XRF das amostras analisadas [22-25]. A Figura 2 apresenta os espectros das amostras de escória de convertedor, de panela, assim como os espectros dos geopolímeros sintetizados a partir de ambas como recebidas, respectivamente. 
a)

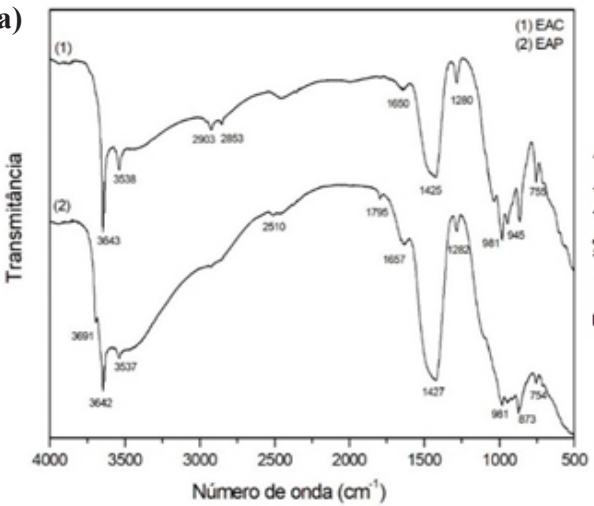

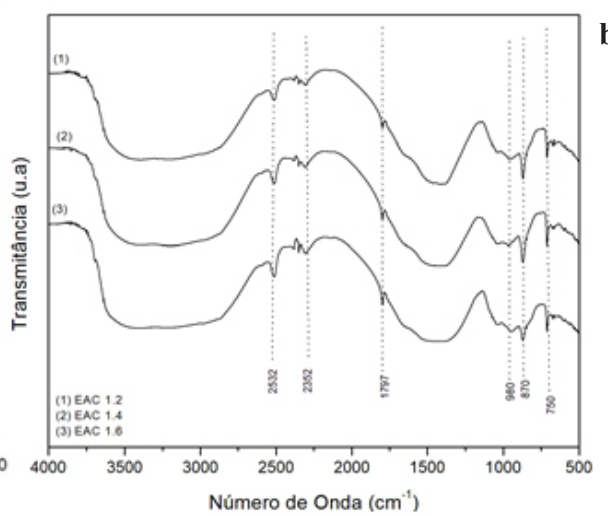

c)



Figura 2: Espectro de FTIR das escórias de panela (LF) e convertedor (LD) (a); geopolímeros da escória de convertedor LD (b) e geopolímeros da escória de panela (LF) (c), respectivamente.

Os espectros das escórias de aciaria de convertedor e de panela apresentaram as seguintes bandas dos grupos funcionais presentes nas regiões correspondentes em: $3690 \mathrm{~cm}^{-1}$ (estiramento do grupo hidroxila estrutural do silicato de alumínio) [31, 32], $3643-3642 \mathrm{~cm}^{-1}$ (estiramento da hidroxila do hidróxido de cálcio), $3538-3537 \mathrm{~cm}^{-1}$ (estiramento do grupo hidroxílico dos compostos de alumínio hidratado), $2903 \mathrm{~cm}^{-1}$ (vibração de alongamento simétrica do carbono (CaCO3) e vibração de alongamento de C-H do silicato de cálcio hidratado (CSH)) [43], $1795 \mathrm{~cm}^{-1}$ (alongamento de C-O dos íons CO2-3 e a vibração da ligação de hidrogênio) $1657-1650 \mathrm{~cm}^{-1}$ (vibração de estiramento de O-H e flexão da água estrutural da escória), 1427-1425 $\mathrm{cm}^{-1}$ (flexão $\mathrm{CO}_{3}$ da calcita e alongamento simétrico C-O do CO2-3) [31-32], $1282-1280 \mathrm{~cm}^{-1}$ (alongamento simétrica do $\mathrm{SiO} 4$ tetraédrico) [45], $981 \mathrm{~cm}^{-1}$ (estiramento Si-O de sílica e silicatos; bandas de absorção correspondentes às vibrações do hidróxidos de alumínio presente no $\mathrm{Al}(\mathrm{OH})_{3}$ e hidróxidos de ferro presente na hematita) [31], $870 \mathrm{~cm}^{-1}$ (alongamento simétrico do grupamento Si-O-Si e estiramento assimétrico do grupo funcional C-O) [33,45], 755 $-754 \mathrm{~cm}^{-1}$ (vibrações de alongamento Al-O, o que indica a presença de alumínio na escória como compostos representativo de aluminatos $\left(\mathrm{Al}_{2} \mathrm{O}_{3}\right)$ nos silicatos) [31].

Em contrapartida, os espectros dos geopolímeros apresentados indicaram as bandas dos grupos funcionais produzidos durante as sínteses: 2532-2510 $\mathrm{cm}^{-1}$ (estiramento simétrico do grupamento C-O) [30, 35]; 1797-1725 cm-1 (alongamento simétrico do grupamento (C-O) presente no íon $\mathrm{CO}_{2}^{-3}$ e à vibração da banda de hidrogênio ligada ao carbono) [31, 33]; 980 $\mathrm{cm}^{-1}$ (estiramento simétrico de Si-OH) [35, 37]; $870 \mathrm{~cm}^{-1}$ (estiramento simétrico de Si-O; estiramento simétrico de T-OH (T $=\mathrm{Si}, \mathrm{Al}$ )) $[30,33,37]$ e $750 \mathrm{~cm}^{-1}$ (alongamento assimétrico de $\mathrm{Si}-\mathrm{O}-\mathrm{Si}$ e alongamento Al-O e indica a presença compostos aluminossilicatos) [33, 37]. Observou-se maior intensidade para banda correspondente a $2532 \mathrm{~cm}^{-1}$ para o geopolímero de escória de panela LF, em relação aos geopolímeros de escória de convertedor LD, devido à presença de maior fração de calcita em sua composição. Essa observação é corroborada pelos dados obtidos a partir das técnicas de XRF e XRD.

Entretanto, as bandas dos espectros de FTIR dos respectivos geopolímeros indicaram a interação do ativador utilizado $(\mathrm{KOH})$, suas interações e formação das estruturas com as escórias durante síntese de geopolimerização. A identificação sugeriu que a presença dos íons cátions de $\mathrm{K}^{+}$que possibilitou a ocorrência da formação de ligações com outros grupamen-

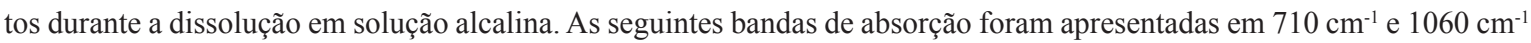
(forte vibração do estiramento simétrico de $\mathrm{K}-\mathrm{O}-\mathrm{S}=\mathrm{O}$ ); $1100 \mathrm{~cm}^{-1}$ (forte vibração do estiramento simétrico de K-O-S-O); $1725 \mathrm{~cm}^{-1}$ (forte vibração do estiramento assimétrico axial de $\mathrm{K}-\mathrm{Mn}=\mathrm{O}$ ); $2330 \mathrm{~cm}^{-1}$ (forte vibração do estiramento simétrico 
do grupo hidroxila de $\mathrm{K}-\mathrm{OH}-\mathrm{S}=\mathrm{O}$ ); $2600 \mathrm{~cm}^{-1}$ (vibração forte correspondente ao estiramento simétrico do grupo hidroxila de $\mathrm{K}-\mathrm{OH}-\mathrm{C}=\mathrm{O}$ ) e $2380 \mathrm{~cm}^{-1}$ (vibração fraca do estiramento simétrico do grupo hidroxila em $\mathrm{K}-\mathrm{OH}-\mathrm{C}=\mathrm{O}$ ) [39, 40].

\subsection{Análise de Difração de raios X (DRX)}

Os padrões de DRX das escórias de aciaria (convertedor e panela) pura e os geopolímeros produzidos com as diferentes proporções de sólido / líquido são mostrados nas Figuras 3 e 4.
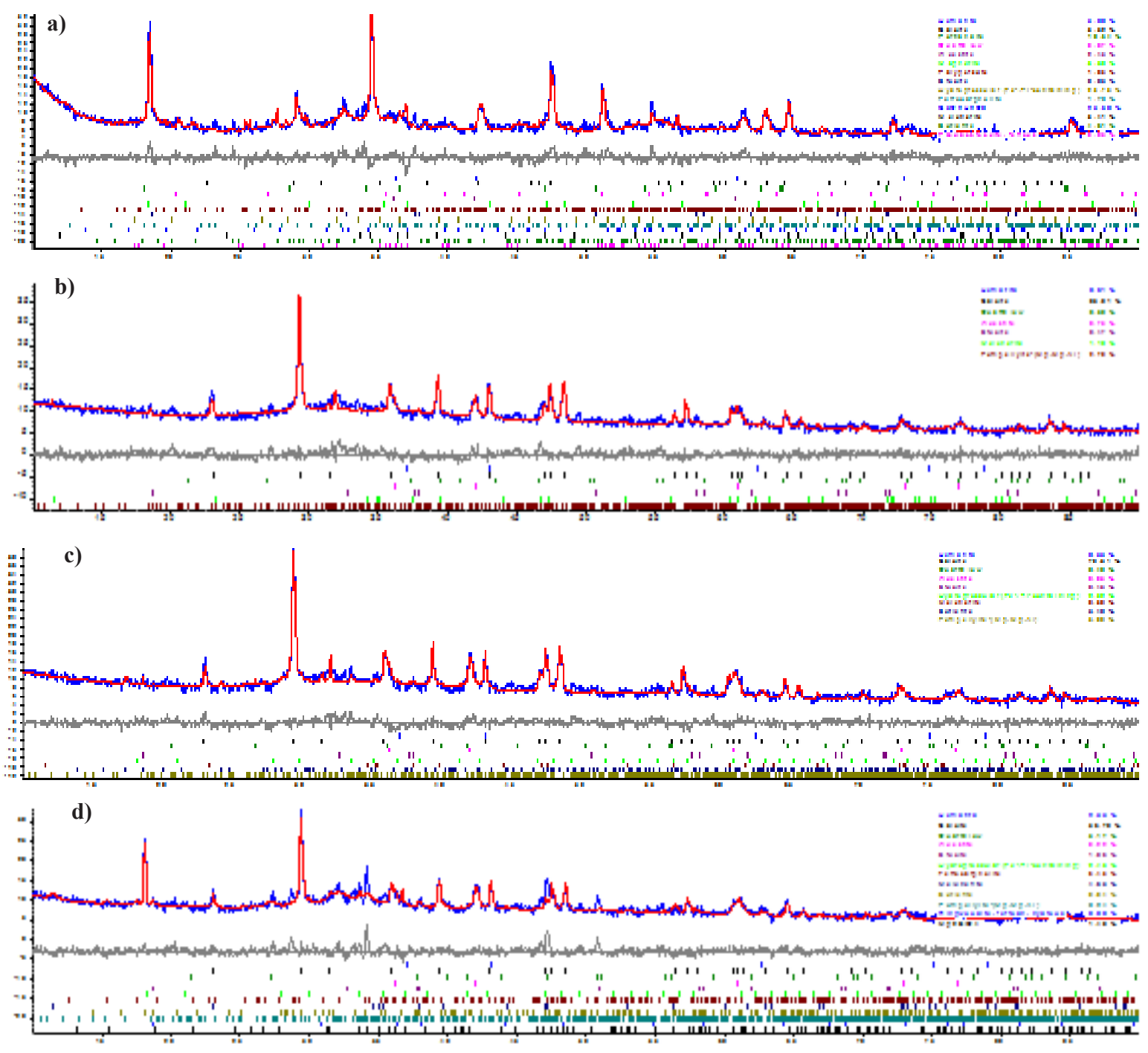

Figura 3: Difratograma das amostras da escória de convertedor (LD) (a), Geopolímero LD 1.2 (b), Geopolímero LD 1.4 (c) e Geopolímero LD 1.6 (d), respectivamente.

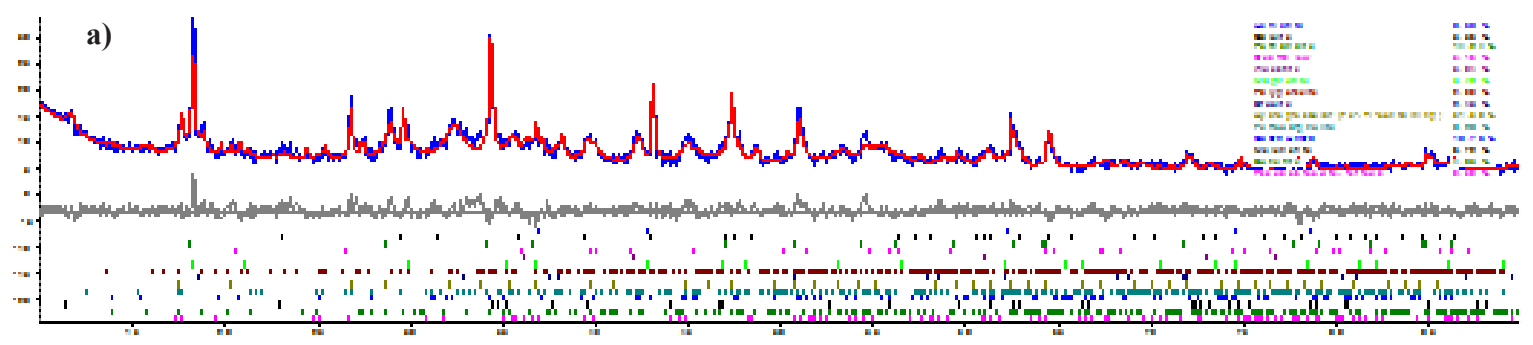



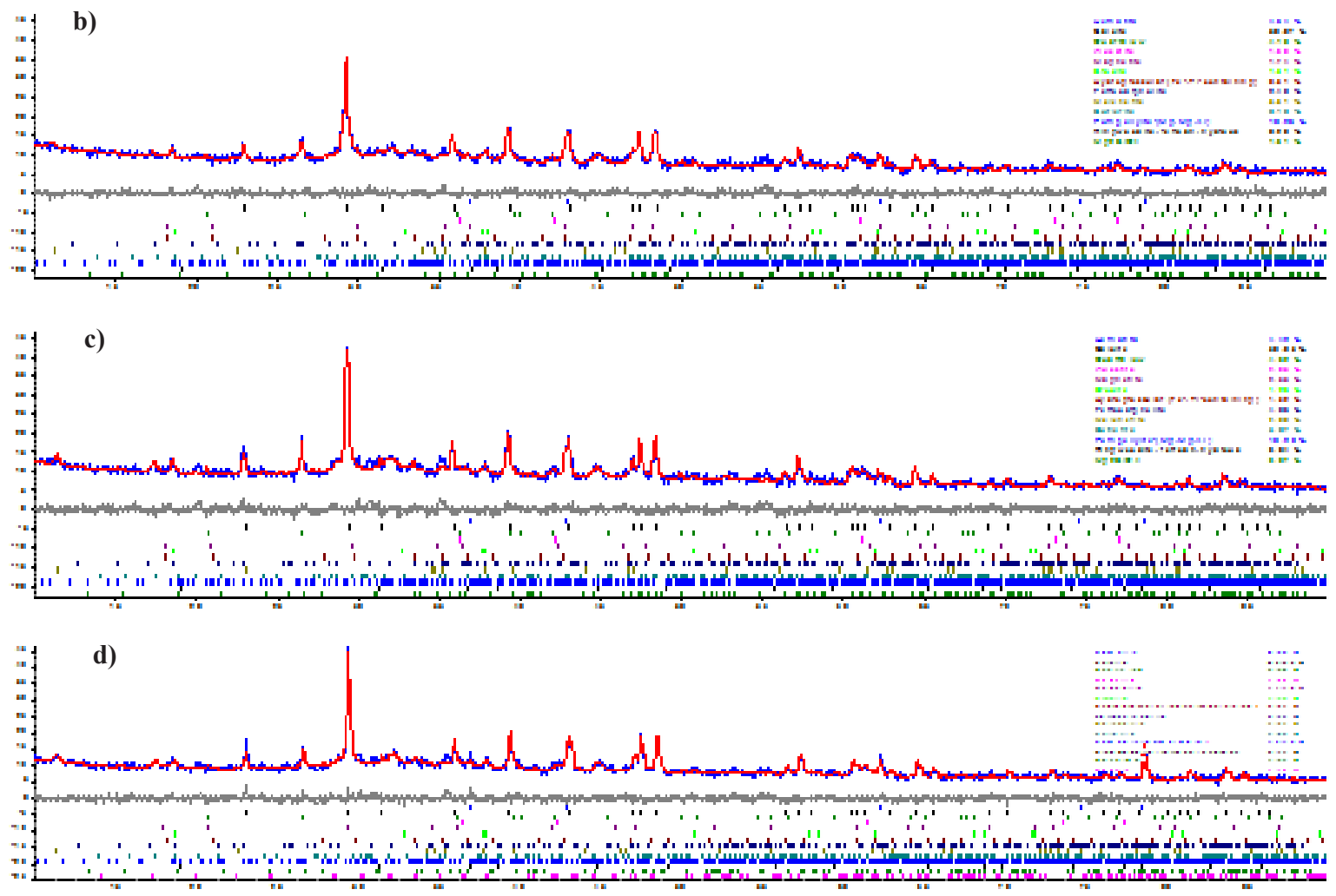

Figura 4: Difratograma das amostras de aciaria de panela (LF) (a), Geopolímero LF 1.2 (b), Geopolímero LF 1.4 (c) e Geopolímero LF 1.6 (d), respectivamente.

Na Tabela 3 foram relacionadas as possíveis fases identificadas para as amostras de aciaria de convertedor e de panela, sendo identificadas algumas fases distintas e ricas em Fe, e que podem corroborar com os resultados obtidos no XRF. Os resultados apresentados das fases e percentuais nessa técnica são dados semiquantitativo, devido à natureza híbrida do material e de sua origem siderúrgica.

Tabela 3: Quantificação das fases presentes nas escórias de panela e escória de convertedor

\begin{tabular}{|c|c|c|c|}
\hline Fases & Fichas & EAP (\%) & EAC (\%) \\
\hline $\mathrm{Fe}_{2} \mathrm{O}_{3}$ - Hematita & 15480 & 8,60 & 5,99 \\
\hline $\mathrm{CaCO}_{3}-$ Calcita & 18166 & 5,56 & 5,52 \\
\hline $\mathrm{Ca}(\mathrm{OH})_{2}-$ Portlandita & 15471 & 14,24 & 18,64 \\
\hline $\mathrm{SiO}$ - Quartzo & 79634 & 5,16 & 0,97 \\
\hline $\mathrm{FeO}$ - Wuesita & 53519 & 3,04 & 2,45 \\
\hline $\mathrm{Fe}_{2} \mathrm{O}_{4}-$ Magnetita & 26410 & 3,42 & 3,59 \\
\hline $\mathrm{Mg}_{2} \mathrm{~A}_{13}\left(\left(\mathrm{Si}_{3} \mathrm{Al}\right) \mathrm{O}_{10}\right)(\mathrm{OH})_{8}-$ Paligorsquita & 16910 & 2,98 & 1,93 \\
\hline $\mathrm{Mg}(\mathrm{OH})_{2}$ - Brucita & 64722 & 2,43 & 0,93 \\
\hline $\mathrm{Ca}_{3} \mathrm{AlFe}\left(\mathrm{SiO}_{4}\right)(\mathrm{OH})_{8}-$ Hydrogrossular $(\mathrm{Fe})$ & 194815 & 31,58 & 23,73 \\
\hline $\mathrm{A}_{14} \mathrm{Fe}_{1.52} \mathrm{H}_{8} \mathrm{Mg}_{0.48} \mathrm{O}_{2} 0 \mathrm{Si}_{4}$ - Ferrocarfolita & 72894 & 0,29 & 1,70 \\
\hline $\mathrm{CaO}_{2}\left(\mathrm{H}_{2} \mathrm{O}\right)_{8}$ - Peroxido de cálcio octahidratado & 38168 & 10,76 & 25,68 \\
\hline $\mathrm{Mg}_{6} \mathrm{~A}_{12}(\mathrm{OH})_{18} 4\left(\mathrm{H}_{2} \mathrm{O}\right)-$ Meixnerita & 107629 & 6,72 & 3,41 \\
\hline $\mathrm{Fe}^{3+}\left(\mathrm{SO}_{4}\right)(\mathrm{OH}) 2\left(\mathrm{H}_{2} \mathrm{O}\right)-$ Butlerita & 15199 & 4,83 & 4,61 \\
\hline $\mathrm{Fe}_{2} \mathrm{TiO}_{5}$ - Pseudobroquita - ferroso & 51225 & 0,39 & 0,85 \\
\hline
\end{tabular}


Os difratogramas das amostras foram indexados pelo software TOPAS-Academic versão 4.1, e para o refinamento foi utilizando o método Rietveld, que representa uma comparação dos dados experimentais com os dados teóricos através de ajustes matemáticos. Os dados experimentais foram representados pela linha em azul e os dados de ajuste pela linha em vermelho, e a diferença entre eles representada pela linha cinza. Os dados teóricos se baseiam em fichas cristalográficas utilizadas fichas do banco de dados do ICSD. Assim, através dos ajustes realizados, foi possível determinar as fases presentes, bem como o seu percentual.

As Figuras 3 (a) e 4 (a) mostram a composição complexa das escórias de aciaria LD e LF, que contém as fases descritas na Tabela 3. Observa-se que nos demais digratogramas ocorreu o surgimento de pico de difração próximo $29^{\circ}(2 \theta)$ e o desaparecimento do pico de difração próximo $19^{\circ}(2 \theta)$. As Figuras 3 e 4 (b) (c) e (d), indicando a formação do geopolímero [27], através dos picos indicados, que sugerem a formação da rede tridimensional de aluminossilicatos correspondente ao geopolímero [42]. Esse efeito é um indicativo da reação do processo de geopolimerização, ou seja, certo grau de reação química entre o componente de escória de alto forno e solução alcalina.

O processo de geopolimerização das amostras pó ser observado pela redução do percentual da fase calcita nas amostras de geopolímeros formados, distintas dessa fase majoritária nos materiais precursores de acordo com os dados de XRF. Esse efeito de redução corresponde à 15\% para os geopolímeros de escória de convertedor LD e 10\% para escória de panela LF. Um fator indicativo da reação de geopolimerização, ou seja, a reorganização da estrutura cristalina durante a síntese. As amostras proporção 1.2, possuíram o maior percentual da presença da calcita, o que pode indicar parte da escória não reagida (Figura 6 (b) e Figura 7 (b)), respectivamente.

\subsection{Termogravimetria (TGA) e Análise Térmica Diferencial (DTA)}

As Figuras 5a e 6a mostram os resultados dos ensaios de análises termogravimétricas (TGA), enquanto as Figuras 5b e 6b apresentam os resultados da análise termogravimétrica diferencial (DTA) dos materiais precursores e dos geopolímeros sintetizados, ambos ensaios foram realizados com a faixa de aquecimento de $25^{\circ} \mathrm{C}$ até $1000^{\circ} \mathrm{C}$.
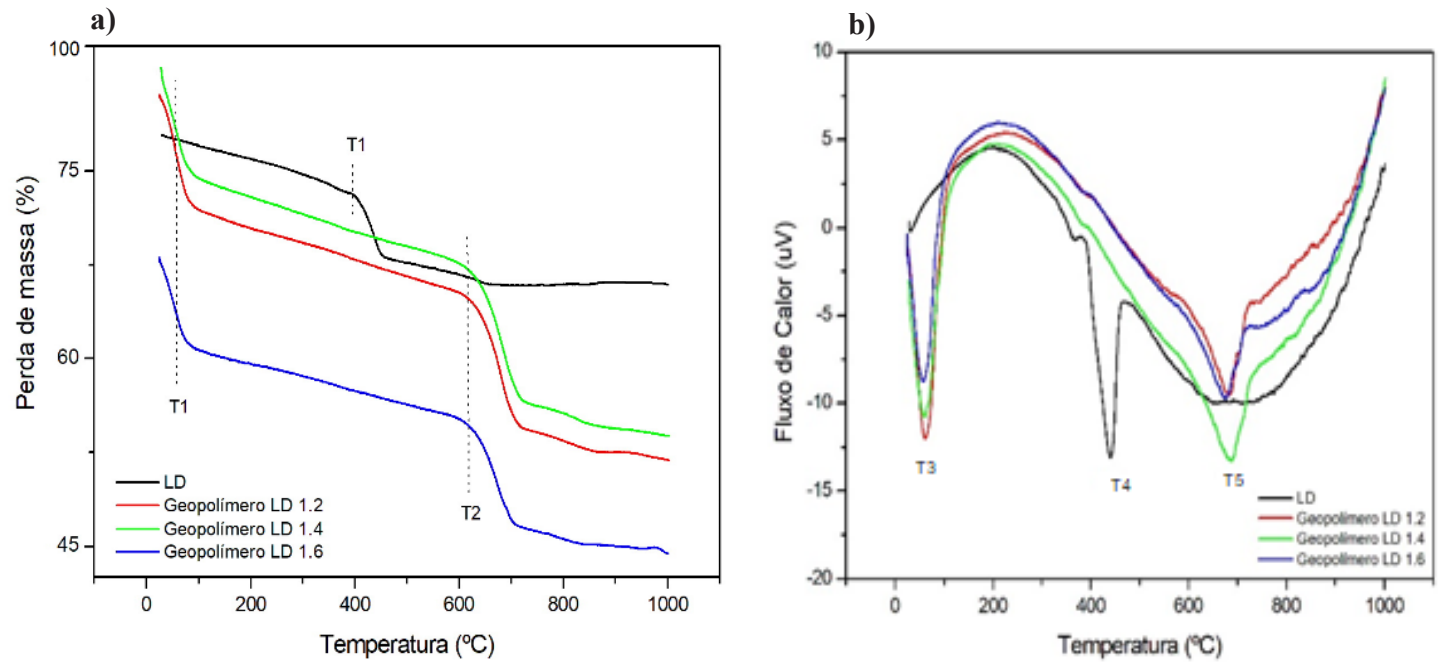

Figura 5: Gráfico de termogravimetria da escoria LD e seus geopolímeros (a). gráfico de análise térmica diferencial da escória LD e seus geopolímeros (b)

A partir das análises entre as curvas de TGA das escórias e dos geopolímeros foi observada uma maior perda de massa na temperatura $\mathrm{T}_{1}$ para as escórias de panela e convertedor. As temperaturas $\mathrm{T}_{1}$ para as escórias de panela e convertedor são $408^{\circ} \mathrm{C}$ e $415^{\circ} \mathrm{C}$, respectivamente. Esses eventos foram relacionados à liberação de hidroxila presente nos materiais e às decomposições da portlandita $\left(\mathrm{Ca}(\mathrm{OH})_{2}\right)$, da hidrocalcita, e do óxido de magnésio (MgO) [29]. Entretanto as temperaturas $\mathrm{T}_{1}$ que foram apresentadas pelos geopolímeros sintetizados foram deslocados para patamares menores, próximos de $100^{\circ} \mathrm{C}$, e foram atribuídas ao efeito de cura que ocorre pela liberação de umidade presente nos materiais de aluminossilicatos e carbonatos. O efeito pode ser indicativo da perda gradual de água absorvida durante a síntese de geopolimerização. As temperaturas foram visualizadas em regiões próximas de $700^{\circ} \mathrm{C}$, o que podem indicar a decomposição do carbonato de cálcio e grupamentos $\mathrm{T}-\mathrm{OH}(\mathrm{T}=\mathrm{Si}, \mathrm{Al})$ presentes nas amostras [28-30; 41-44]. Essa faixa de degradação entre $400^{\circ} \mathrm{C}-700^{\circ} \mathrm{C}$ pode ser associada à perda de massa devido à desidroxilação da sílica, como foi observado por Ramos e Mendes [40]. 
a)

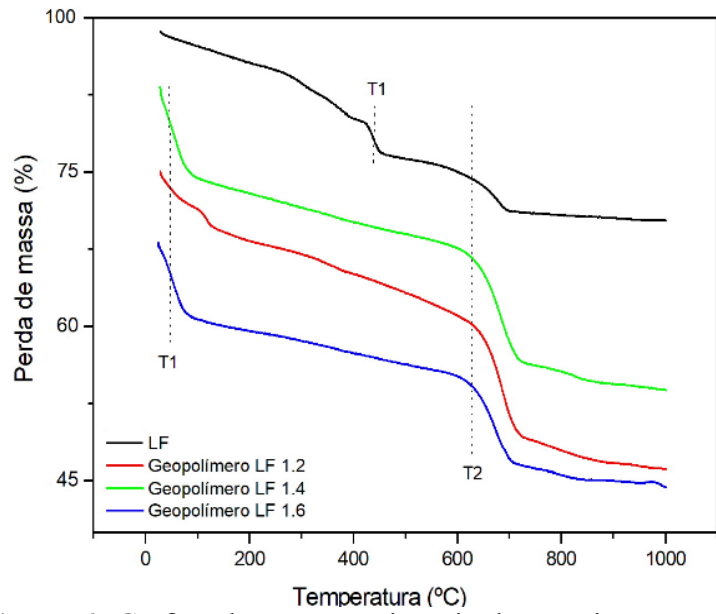

b)

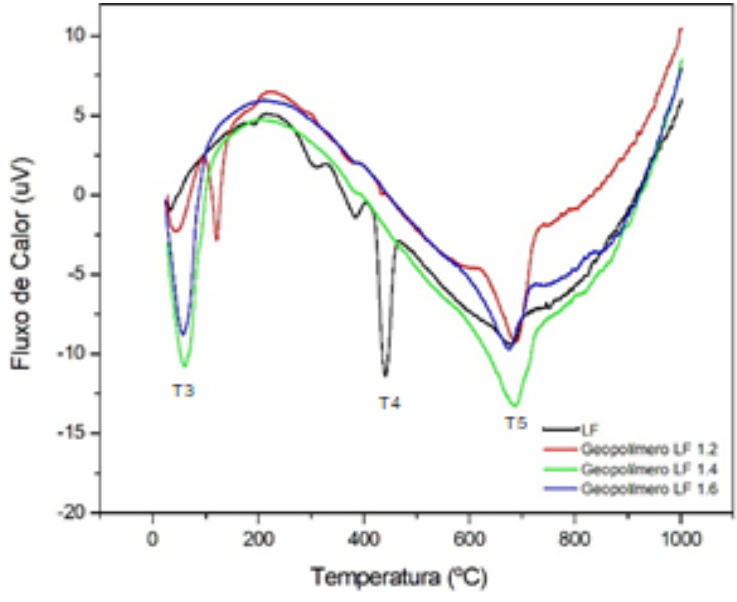

Figura 6: Gráfico de termogravimetria da escoria LF e seus geopolímeros (a). gráfico de análise térmica diferencial da escória LF e seus geopolímeros (b).

$\mathrm{Na}$ Tabela 4 estão relacionadas às temperaturas dos eventos obtidos nas análises de termogravimetria e termogravimetria diferencial

Tabela 4: Análises de termogravimetria e termogravimetria diferencial correspondente aos materiais puros e geopolimerizados, respectivamente.

\begin{tabular}{ccccccc}
\hline AMOSTRA & \multicolumn{4}{c}{ TGA } & DTA \\
\cline { 2 - 5 } & $\mathbf{T}_{1}\left({ }^{\circ} \mathbf{C}\right)$ & $\mathbf{T}_{2}\left({ }^{\circ} \mathbf{C}\right)$ & RESíDUO (\%) & $\mathbf{T}_{3}\left({ }^{\circ} \mathbf{C}\right)$ & $\mathbf{T}_{4}\left({ }^{\circ} \mathbf{C}\right)$ & $\mathbf{T}_{5}\left({ }^{\circ} \mathbf{C}\right)$ \\
\hline Escória de Panela & 415,68 & 648,74 & 79,36 & --- & 440,64 & 677,60 \\
\hline Geopolímero de Panela 1.2 & 104,09 & 656,32 & 61,89 & 43,13 & --- & 686,97 \\
\hline Geopolímero de Panela 1.4 & 96,73 & 682,45 & 62,87 & 51,76 & --- & 700,69 \\
\hline Geopolímero de Panela 1.6 & 54,04 & 695,96 & 63,18 & 52,48 & --- & 694,44 \\
\hline Escória de Convertedor & 408,03 & 642,11 & 84,66 & --- & 440,93 & 679,95 \\
\hline Geopolímero de Convertedor 1.2 & 61,42 & 684,87 & 64,08 & 61,30 & --- & 683,81 \\
\hline Geopolímero de Convertedor 1.4 & 65,42 & 689,33 & 65,06 & 59,00 & --- & 686,00 \\
\hline Geopolímero de Convertedor 1.6 & 54,83 & 673,28 & 65,60 & 56,34 & --- & 675,13 \\
\hline
\end{tabular}

As maiores frações de resíduos gerados pelas escórias, em comparação às frações geradas pelos geopolímeros podem ser indicativas da efetiva síntese e ligação entre os componentes presentes na solução alcalina de $\mathrm{KOH}$ durante processo de síntese pelos geopolímeros produzidos, assim como a reação entre os materiais aluminossilicatos e suas modificações durante a síntese. O maior percentual de resíduos das amostras de escória de panela e seus geopolímeros, em relação às amostras de escória de convertedor e seus geopolímeros (Tabela 4), demonstra uma maior estabilidade térmica desses materiais, o que pode corroborar a presença de algumas formações identificadas pelos resultados das análises de FRX (Tabela 1) que apontam maior percentual de $\mathrm{MgO}$ nas amostras provenientes de escória de panela.

Os resultados relacionados aos eventos de DTA, pelas temperaturas $\mathrm{T}_{3}$ não foram apresentadas nas curvas de ambas as escórias, entretanto para as amostras geopoliméricas de ambos os materiais precursores (escória de panela e convertedor) indicaram os eventos de perda de umidade nas temperaturas $\mathrm{T}_{3}$ nos patamares de $100^{\circ} \mathrm{C}$, o que foram atribuídos à desidratação do silicato de cálcio (CSH), do aluminato de cálcio e do hidróxido de cálcio [28, 29]. As temperaturas $\mathrm{T}_{4}$ referentes às duas escórias estão relacionadas à desidratação da Portlandita $\left(\mathrm{Ca}(\mathrm{OH})_{2}\right)$ e decomposição da hidrocalcita ocorridas próximas de $400^{\circ} \mathrm{C}[29,41]$. Os eventos respectivos às temperaturas $T_{5}$ são apresentados em regiões próximas de $700^{\circ} \mathrm{C}$, e são relacionados à decomposição dos carbonatos presentes em todas as amostras [28-30].

\subsection{Microscopia Eletrônica de Varredura (MEV-FEG)}

As análises em microscopia eletrônica de varredura com fonte de emissão de campo (MEV-FEG) das amostras de geopolímeros, escória de aciaria de convertedor LD e panela LF são apresentadas nas Figuras 7 e 8 . A ativação alcalina das escórias possibilitou a dissolução dos materiais de aluminossilicatos que se ligaram para formação de estruturas dispersas na microestrutura da superfície e seu interior [25].

A partir da observação das microestruturas, foi possível a observação de formas e a texturas diferenciadas nas su- 
perfícies dos materiais puros e sintetizados. As partículas das escórias apresentaram formas geométricas com superfícies rugosas. Nas Figuras 7 (b e c) e Figuras 8 (b e c) foi possível a observação de regiões das escórias não reagidas, com maior rugosidade e espaços livres os quais são formadores da estrutura porosa heterogênea que apresentaram formações microestruturais com arestas arredondadas e retangulares, assim como rugosidade superficial.

As Figura 7 (d) e Figura 8 (d) são representativas da superfície das amostras na razão 1.6 g/v que desenvolveu uma estrutura mais compacta e homogênea, o que pode estar associado à quantidade ideal de materiais para que a reação seja eficiente, como descrito na literatura [23].

De acordo com as imagens obtidas por MEV-FEG, pode-se observar que para razões de sólido/líquido menores nas concentrações das escórias, o processo de geopolimerização não obteve a eficiência esperada, em relação aos corpos de provas com as maiores concentrações das escórias, como pode ser visualizado nas Figuras 7 (d) e Figura 8 (d), que apresentam aspecto mais denso. Esses resultados corroboram com os resultados obtidos através do ensaio de do princípio de Arquimedes, que indicam que o valor da densificação foi elevado proporcionalmente pela razão sólido/líquido.

a)

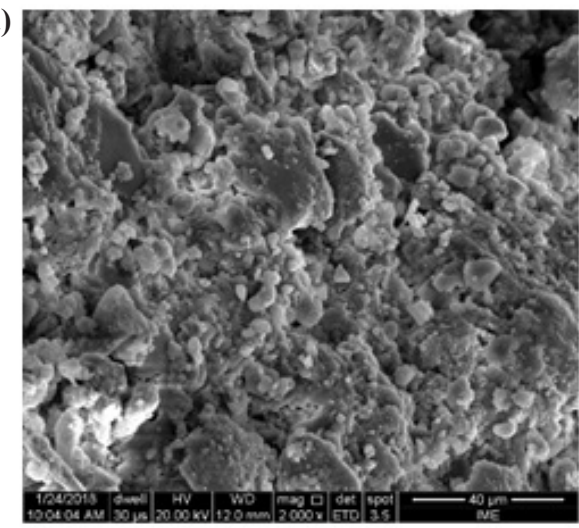

c)

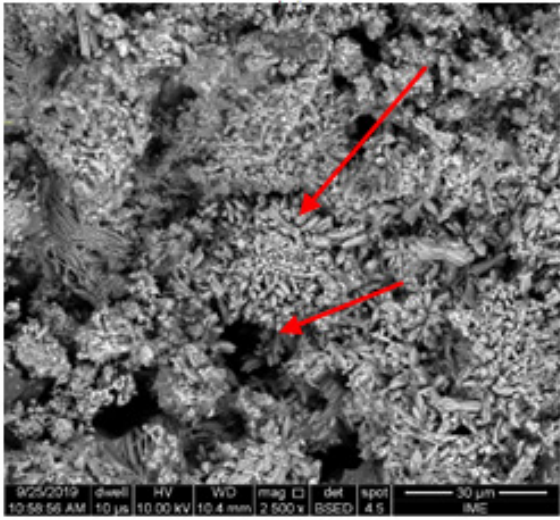



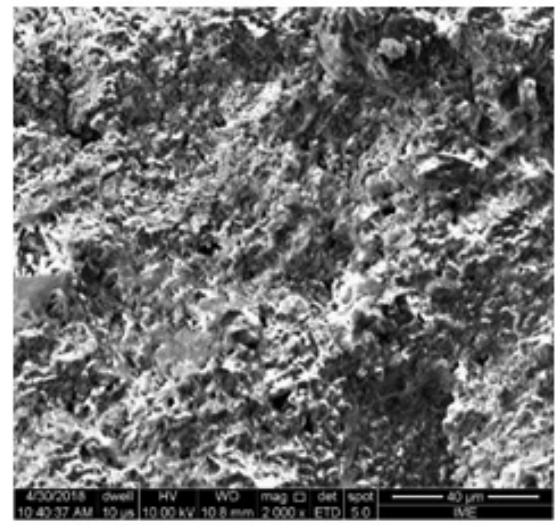

d)

Figura 7: Micrografias (MEV-FEG) da escoria panela LF (a), dos geopolímeros geopolímero LF 1.2 (b), geopolímero LF 1.4 (c) e geopolímero LF 1.6 (d), respectivamente.

a)

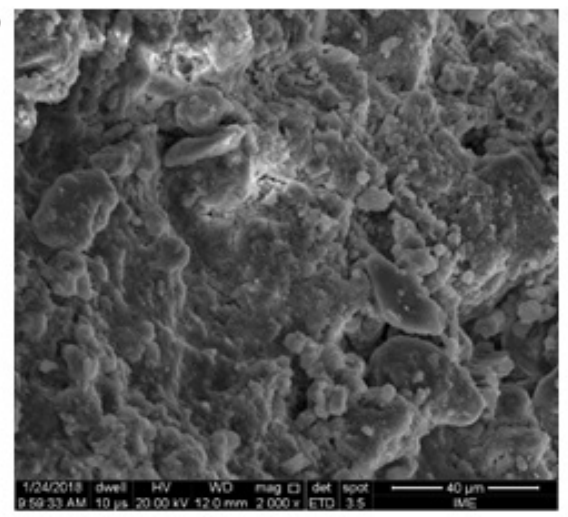

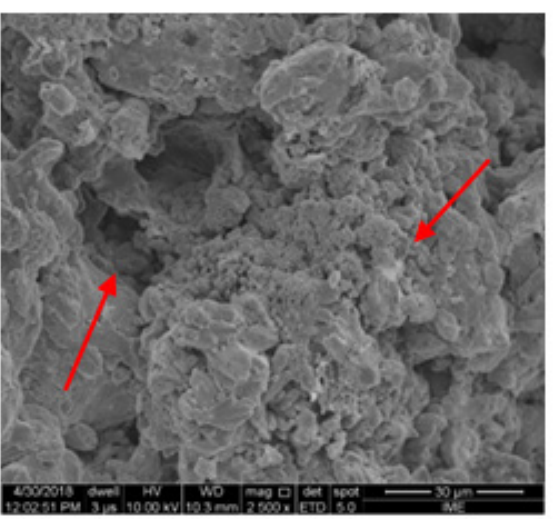

b) 
c)

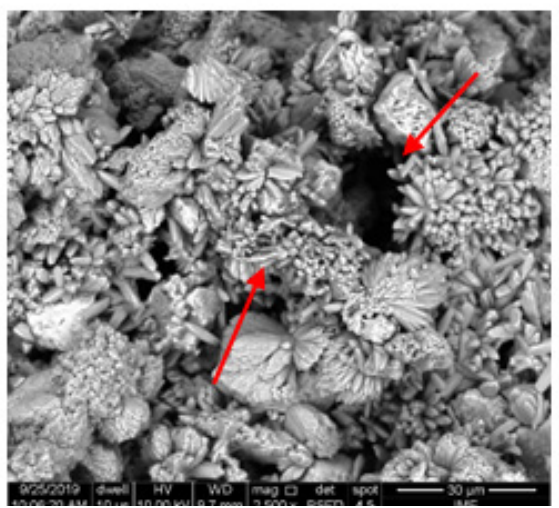

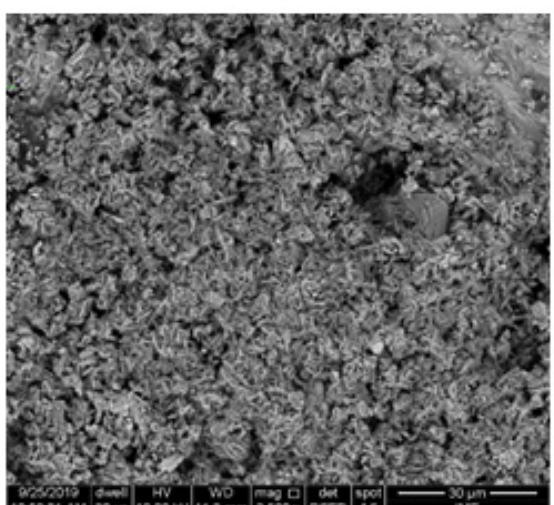

d)

Figura 8: Micrografias (MEV-FEG) da escoria de aciaria de convertedor LD (a), das amostras de geopolímero LD 1.2 (b), geopolímero LD 1.4 (c) e geopolímero LD 1.6 (d), respectivamente.

\section{CONCLUSÕES}

A pesquisa concluiu que o processo de geopolimerização das escórias de panela e convertedor foi eficiente. Os resultados da síntese indicaram que os materiais adquiridos possuem funcionalidade e versatilidade para produção de materiais inovadores. De acordo com o estudo, a utilização dos resíduos de siderurgia pode caracterizar esse processo como uma rota sustentável para a fabricação de materiais com propriedades avançadas.

Os resíduos industriais empregados indicaram que o teor de aluminossilicatos influenciou os resultados obtidos para cada tipo de amostra, assim como o material para alcalinização da solução $(\mathrm{KOH})$ obteve boa influência na moldagem dos corpos-de-prova das amostras moldadas. Portanto, um dos destaques da pesquisa aponta para a obtenção de materiais avançados, com propriedades adequadas para diversas funcionalidades, assim como o apelo à sustentabilidade, uma vez que se utilizaram resíduos industriais provenientes da indústria siderúrgica.

Os resultados que apresentaram produtos geopoliméricos com maiores densificações foram obtidos a partir de amostras em concentrações sólido/líquido como valor de 1.6, fator que apntou para produção de materiais que necessitem maior coesão entre as partículas. Enquanto as razões 1.2 e 1.4, que apresentaram maior porosidade, podem ser consideradas na produção de materiais com porosidade, para melhor desempenho mecânico e acústico em algumas funcionalidades.

$\mathrm{O}$ agente de alcalinização $\mathrm{KOH}$, da solução precursora, foi observado ter influência na formação microestrutural dos materiais adquiridos, os quais apresentaram diferenciadas morfologias, adquiridas durante o processo de cura dos materiais, e influenciaram alterações na estabilidade térmica das amostras.

As diferentes densificações, estabilidade térmica, dimensional, e porosidade apresentaram influências diretas entre os teores de sólido/líquido, assim como o tipo de precursor de alcalinização das soluções, quando comparadas aos resultados observados na literatura.

Portanto, a síntese dos diferentes geopolímeros apresentados a partir das escórias de convertedor e panela, provenientes da fabricação de aço, é um processo altamente atrativo para futuras aplicações de materiais como com funcionalidade versátil em determinados setores, com apelo ecológico, uma vez que há diminuição da poluição gerada através desses resíduos industriais gerados pela indústria siderúrgica.

\section{AGRADECIMENTOS}

Os autores agradecem à Coordenação de Aperfeiçoamento de Pessoal de Nível Superior (CAPES), Conselho Nacional de Desenvolvimento Científico e Tecnológico (CNPq), Instituto de Pesquisas da Marinha (IPqM), Centro Brasileiro de Pesquisas Físicas (CBPF) e ao Instituto Militar de Engenharia (IME) pelo apoio técnico-financeiro e à Usiminas pelo fornecimento dos materiais de resíduos de aciaria.

\section{BIBLIOGRAFIA}

[1] DAVIDOVITS, J. "Geopolymers-Inorganic Polymeric New Materials", Journal of Thermal Analysis and Calorimetry, v. 37, pp. $1633-1656,1991$.

[2] PROVIS, J.L., LUKEY, G.C., VAN DEVENTER, J.S.J. “Do Geopolymers Actually Contain Nanocrystalline Zeolites? A Reexamination of Existing Results", Chemistry of Materials. v.17, pp. 3075-3085, 2005,

[3] SONGPIRIYAKIJ, S., KUBPRASIT, T., JATURAPITAKKUL, C., et al.Compressive strength and degree of reaction of biomass- and fly ash-based geopolymer. Construction and Building Materials, [s.1.], Elsevier BV; v. 24, n. 3, p.236-240, mar. 2010. 
[4] DAVIDOVITS, J., HUAMAN, L., DAVIDOVITS, R. Ancient geopolymer in south American monument. SEM and petrographic evidence. Materials Letters, [s.1.], Elsevier BV; v. 235, p.120-124, jan. 2019.

[5] ABOULAYT, A., RIAHI, M., TOUHAMI, O.M., et al.Properties of metakaolin based geopolymer incorporating calcium carbonate. Advanced Powder Technology, [s.1.], v. 28, n. 9, p.2393-2401, set. 2017.

[6] ABDUllah, M.M., KAMARUdin, H., BNHUSSAIN, M., et al.Mechanism and Chemical Reaction of Fly Ash Geopolymer Cement- A Review, Asian Journal of Scientific Research, 2011, vol. 6, issue 5, pp. 35-44.

[7] VAN JAARSVELD, J.G.S, VAN DEVENTER, J.S.J, LORENZEN, L. "The Potential Use of Geopolymeric Materials to Immobilise Toxic Metals: Part I. Theory and Applications”, Minerals Engineering. v. 10, pp. 659-669, 1997.

[8] VAN JAARSVELD, J.G.S, VAN DEVENTER, J.S.J. SCHWARTZMAN, A. "The Potential Use of Geopolymeric Materials to Immobilise Toxic Metals: Part II. Material and Leaching Characteristics", Minerals Engineering. v. 12, pp. 75-91, 1999.

[9] ALBITAR, M., MOHAMED ALI, M.S., VISINTIN, P. "Experimental Study on Fly Ash and Lead Smelter Slag-Based Geopolymer Concrete Columns", Construction and Building Materials. v. 141, pp. 104-112, 2017.

[10] PROVIS, J.L., VAN DEVENTER, J.S.J. Geopolymers: Structures, Processing, Properties and Industrial Applications, 1 ed., Elsevier, 2009.

[11] PROVIS, J.L., PALOMO, A, SHI, C. "Advances in Understanding Alkali-Activated Materials", Cement and Concrete Research.v. 7, p. 110, 2015.

[12] PAISITSRISAWAT, P., RATTANASAK, U. "Effect of Silica Fume on Properties of Fluidizer Bed Combustion (FBC) Fly Ash Geopolymer", Journal of Industrial Technology. v. 9, p. 1, 2013.

[13] ALlAHVERDI, A., SKVARA, F. "Nitric Acid Attack on Hardened Paste of Geopolymeric Cements", Ceramics Silikaty. v. 45, p. 81, 2001.

[14] SHI, C.A., PALOMO, A., PROVIS, J.L. "Advances in Understanding Alkali-Activated Materials", Cement and Concrete Research. v. 78, p. 110, 2015.

[15] LI, Y., SUN, Y. "Preliminary Study on Combined-Alkali-Slag Paste" Cement and Concrete Research. v. 30, pp. $963-$ 966, 2000.

[16] PROVIS, J.L., DUXSON, P., VAN DEVENTER, et al."The Role of Mathematical Modelling and Gel Chemistry in Advancing Geopolymer Technology”, Chemical Engineering Research and Design. v. 83, pp. 853-860, 2005.

[17] AVALCANTE, E. S. B., BESSA, I. S., CASTELO BRANCO, V.T.F., et al.Dosagem de misturas asfálticas segundo a metodologia superpave utilizando escória de aciaria como agregado. In: IV Simpósio Internacional de Avaliação de Pavimentos e Projetos de Reforço (SINAPPRE), 2009.

[18] ROHDE, L., NÚÑEZ, W. P., CERATTI, J. A. P. Electric Arc Furnace Steel Slag: Base Material for Low-Volume Roads. Transportation Research Record: Journal of the Transportation Research Board, [s.1.], v. 1819, n. 1, pp.201-207, jan. 2003. SAGE Publications.

[19] DUXSON, P., PROVIS, J.L., LUKEY, G.C., et al."Understanding the Relationship Between Geopolymer Composition, Microstructure and Mechanical Properties”, Colloids and Surfaces A: v. 269, pp. 47-58, 2005, 2005.

[20] LEE, W.K.W., VAN DEVENTER, J.S.J., "Structural Reorganization of Class F Fly Ash in Alkaline Silicate Solutions", Colloids and Surfaces A, v. 211, pp. 49-66, 2002.

[21] RAHIER, H., VAN MELE, B., WASTIEL, S. J. "Low-Temperature Synthesized Aluminosilicate Glasses. 2. Rheological Transformations During Low-Temperature Cure and High-Temperature Properties of a Model Compound". Journal of Materials Science, v. 30, pp. 80-85, 1996.

[22] DUXSON, P., FERNANDEZ-JIMINEZ A., PROVIS J.L., LUCKEY G.C., et al."Geopolymer Technology: The Current State of The Art”. Journal of Materials Science, v. 42, pp. 2917-33, 2007.

[23] ZHUANG, X.Y, CHEN, L., KOMARNENI, S., et al."Fly Ash-Based Geopolymer: Clean Production, Properties and Applications”. Journal of Cleaner Production, [S.L.], Elsevier Bv., v. 125, pp. 253-267, Jul. 2016.

[24] VILLAS, C., PECINA, E.T., TORRES, R., GÓMEZ, L. "Geopolymer Synthesis Using Alkaline Activation of Natural Zeolite”. Construction and Building Materials, Vol.24, Issue 11, pp. 2084-2090, 2010.

[25] YILDIRIM, I. Z., PREZZI, M. “Geotechnical Properties of Fresh and Aged Basic Oxygen Furnace Steel Slag”. Journal of Materials in Civil Engineering, [S.L.], American Society of Civil Engineers (Asce), v. 27, n. 12, pp.1-11, Dez. 2015. 
[26] ABDEL-GHANI, N.T., ELSAYED, A., HAMDY, A., et al."Geopolymer Synthesis by The Alkali-Activation of Blastfurnace Steel Slag and Its Fire-Resistance”. Hbrc Journal, [S.L.], Elsevier Bv., pp. 1-6, Ago. 2016.

[27] BAI, T, SONG, Z, WU, Y, HU, X, BAI, H. "Influence of Steel Slag on The Mechanical Properties and Curing Time of Metakaolin Geopolymer”. Ceramics International, [S.L.], Elsevier Bv., v. 44, n. 13, pp.15706-15713, Set. 2018.

[28] XUQUAN, H, MINGMING, J, XIAORONG, Z, et al. "Mechanical Properties and Hydration Mechanisms of HighStrength Fluorogypsum-Blast Furnace Slag-Based Hydraulic Cementitious Binder”. Construction and Building Materials, [S.L.], Elsevier Bv., v. 127, pp.137-143, Nov. 2016.

[29] ANGULO-RAMÍREZ, EUGENIA, D., GUTIÉRREZ, R.M. DE, et al.“Alkali-Activated Portland Blast-Furnace Slag Cement: Mechanical Properties and Hydration”. Construction and Building Materials, [S.L.], Elsevier Bv., v. 140, pp.119128, Jun. 2017

[30] KOVÁRÍK, T., RIEGER, D., KADLEC, J., et al.“Thermomechanical Properties of Particle-Reinforced Geopolymer Composite with Various Aggregate Gradation of Fine Ceramic Filler”. Construction and Building Materials, [S.L.], Elsevier Bv., v. 143, pp.599-606, Jul. 2017.

[31] NAVARRO, C.; DÍAZ, M.; VILLA-GARCÍA, M. A. "Physico-Chemical Characterization of Steel Slag. Study of Its Behavior Under Simulated Environmental Conditions". Environmental Science \& Technology, [S.L.], American Chemical Society (Acs)., v. 44, n. 14, pp. 5383-5388, 15 Jul. 2010.

[32] AIMOTO, M., KANEHASHI, K., FUJIOKA, Y.. “Analytical Technologies for Steel Slag”. Nippon Steel \& Sumitomo Metal Technical, Report n. 109, July 2015.

[33] WANG, S., PENG, X., TANG L., et al."Influence of Inorganic Admixtures on the $11 \AA$ A-Tobermorite Formation Prepared from Steel Slags: XRD And FTIR Analysis”. Construction and Building Materials, [S.L.], Elsevier Bv., v. 60, pp.42-47, Jun. 2014.

[34] PIQUÉ, T.M., VÁZQUEZ, A. "Uso de espectroscopía Infrarroja com transformada de Fourier (FTIR) en el estúdio de la hidratación del cemento", Concreto y cimento. Investigación y Desarrollo, v.3, n. 2, pp. 62-71, 2012.

[35] YUELIN, Q, HAO, L, YANHUA, Y. "Structure evolution of blast furnace slag with high $\mathrm{Al}_{2} \mathrm{O}_{3}$ Content and 5 mass\% $\mathrm{TiO}_{2}$ via molecular dynamics simulation and fourier transform infrared spectroscopy”. Metallurgical Research \& Technology, [s.1.], v. 115, n. 1, pp.113-119, 28 nov. 2017.

[36] PRUD'HOMME, E., AUTEF, A., ESSAIDI, N., et al."Defining existence domains in geopolymers through their physicochemical properties". Applied Clay Science, [s.1.], Elsevier BV., v. 73, pp. 26-34, mar. 2013.

[37] YASIPOURTEHRANI, S., STREZOV, V., BLIZNYUKOV, S., et al."Investigation of Thermal Properties of Blast Furnace Slag to Improve Process Energy Efficiency”. Journal of Cleaner Production, [s.1.], Elsevier BV., v. 149, pp.137145, abr. 2017.

[38] MILLER, F.A., WILKINS, C.H. Infrared Spectra and Characteristic Frequencies of Inorganic Ions. Analytical Chemistry, V, 24, n. 8, August 1952.

[39] NAKAMOTO, K. Infrared and Raman Spectra of Inorganic and Coordination Compounds. Part A: Theory and Applications in Inorganic Chemistry. 6 ed., Canadá: John Wiley \& Sons, 2009.

[40] RAMOS, F.J.H.T.V., MENDES, L.C., CESTARI, S.P. “Organically modified concrete waste with oleic acid”. Journal of Thermal Analysis and Calorimetry, [s.1.], Springer Science and Business Media LLC., v. 119, n. 3, p.1895-1904, 28 jan. 2015.

[41] DELHOMME, F., AMBROISE, J., LIMAM, A. "Effects of high temperatures on mortar specimens containing Portland cement and GGBFS". Materials and Structures, [s.1.], Springer Science and Business Media LLC., v. 45, n. 11, pp.1685-1692, 6 jun. 2012.

[42] ABDOLLAHNEJAD, Z., LUUKKONEN, T., MASTALI, M., et al."Development of One-Part Alkali-Activated Ceramic/Slag Binders Containing Recycled Ceramic Aggregates". Journal of Materials in Civil Engineering, [s.1.], American Society of Civil Engineers (ASCE), v. 31, n. 2, pp.1-13, fev. 2019.

[43] GUAN, W., JI, F., CHEN, Q., et al. Synthesis and Enhanced Phosphate Recovery Property of Porous Calcium Silicate Hydrate Using Polyethyleneglycol as Pore-Generation Agent. Materials, [s.1.], v. 6, n. 7, pp. 2846-2861, 15 jul. 2013.

[44] PARK, H., PARK, J., KIM, G.H., et al.Effect of TiO2 on the Viscosity and Slag Structure in Blast Furnace Type Slags. Steel Research International, [s.1.], Wiley., v. 83, n. 2, pp.150-156, 13 jan. 2012. 
[45] MOHASSAB, Y.; SOHN, H. Y. Analysis of Slag Chemistry by FTIR-RAS and Raman Spectroscopy: Effect of Water Vapor Content in H2-H2O-CO-CO2 Mixtures Relevant to a Novel Green Ironmaking Technology. Steel Research International, [s.1.], v. 86, n. 7, pp.740-752, 3 out. 2014.

\section{ORCID}

Ana Paula dos Santos Pereira

https://orcid.org/0000-0002-3983-3945

Flavio James Humberto Tomassini Viera Ramos

https://orcid.org/0000-0003-0869-1283

Marcelo Henrique Prado da Silva

https://orcid.org/0000-0002-1182-5345 